Archives de sciences sociales des religions

161 | Janvier-Mars 2013

Messianismes et anthropologie entre France et Italie I Figures et substituts de saints

\title{
Vittorio Lanternari : notice bio-bibliographique
}

\section{Marcello MASSENZIO}

Traducteur : Giordana Charuty

\section{(QpenEdition Journals}

Édition électronique

URL : http://journals.openedition.org/assr/24823

DOI : $10.4000 /$ assr. 24823

ISSN : $1777-5825$

Éditeur

Éditions de l'EHESS

Édition imprimée

Date de publication : 1 avril 2013

Pagination : 25-26

ISBN : 13-978-2-7132-2394-5

ISSN : 0335-5985

Référence électronique

Marcello MASSENZIO, "Vittorio Lanternari : notice bio-bibliographique », Archives de sciences sociales des religions [En ligne], 161 | Janvier-Mars 2013, mis en ligne le 30 mai 2016, consulté le 19 avril 2019. URL : http://journals.openedition.org/assr/24823 ; DOI : 10.4000/assr.24823 


\section{Vittorio Lanternari : notice bio-bibliographique}

Vittorio Lanternari est né, d'une famille juive, à Chiaravalle (Ancône) en 1918 ; il est mort à Rome en août 2010. Après des études classiques, Lanternari s'était inscrit en 1937 à la Faculté des Lettres de Bologne mais la promulgation, en 1938, des lois raciales par le régime fasciste le confronte à l'interdiction d'enseigner : d'où sa réorientation en faculté d'Agronomie où il obtient sa licence en 1942. L'occupation allemande de nombreuses villes italiennes, parmi lesquelles Ancône, oblige le jeune Lanternari à fuir à plusieurs reprises pour échapper aux rafles des nazis ou des fascistes. Parmi les diverses informations que je dois à sa fille Diane, je retiens ce détail émouvant dont Lanternari aimait à se souvenir : un jour, un paysan l'avertit de ne pas rentrer à la maison où des soldats l'attendaient pour le déporter, ce fut une nouvelle fuite avec toute la famille pour chercher refuge en montagne. Ce n'est qu'en 1945 que Lanternari put s'inscrire, à nouveau, en Lettres, à l'Université de Rome où il se prit de passion pour l'histoire des religions. L'intérêt pour ce domaine d'études a certainement été éveillé par la prise de conscience de sa propre "diversité religieuse », murie tout au long d'une enfance vécue dans un pays à forte tradition catholique ; il marquera un tournant dans son existence.

Vittorio Lanternari a, lui-même, composé un sobre récit autobiographique pour identifier les temps forts de son itinéraire de chercheur (V. Lanternari, La mia alleanza con Ernesto De Martino, Liguori, Napoli, 1997). En premier lieu, vient la rencontre avec celui qui sera son Maître, Raffaele Pettazzoni, le fondateur de l'histoire des religions en Italie et, dans le même temps, le fondateur du premier Institut d'Ethnologie auprès de l'Université La Sapienza de Rome : "C'était, tout juste, la seconde moitié des années 40 ; j'ai fait des études de Lettres à Rome et j'ai préparé une tesi di laurea en ethnologie religieuse avec le professeur Raffaelle Pettazzoni. Tout de suite après, un intérêt très vif pour la découverte de cultures religieuses "autres", orientales et surtout primitives, m'a poussé à suivre l'École de Perfectionnement en Histoire des religions » (ibid. : 1).

Non moins importantes, sur le plan scientifique comme sur le plan personnel, ont été d'autres rencontres : celle d'Angelo Brelich et, surtout, celle d'Ernesto de Martino, avec lequel Lanternari a tissé, à partir de 1948, un intense rapport d'échanges et de collaborations, nourri par la même ferveur dans l'engagement 
politique et social : "Il y avait entre De Martino et moi un courant d'intérêts parallèles (...) Nous étions sortis depuis peu de la guerre contre la dictature fasciste et nous aspirions tous les deux à élargir nos horizons de savoirs en direction de mondes et d'hommes restés, jusque-là, dans l'ombre ou marginalisés » (ibid. : 3). Un tournant ultérieur se dessine, dans cet itinéraire scientifique, avec le passage d'une anthropologie «de cabinet " à l'ethnologie fondée sur l'enquête de terrain : parmi les résultats les plus significatifs de ce souci ethnographique, mentionnons Dei Profeti Contadini (1988) qui présente les résultats d'une recherche conduite parmi les Nzima du Ghana à travers une succession d'expéditions entre 1971 et 1977.

Titulaire d'une chaire d'ethnologie et d'histoire des religions à l'Université de Bari, puis à l'Université La Sapienza de Rome, Lanternari a donné de nombreux enseignements à l'étranger : à la Columbia University de New York, à l'Institut national d'Anthropologie et d'Histoire de Mexico, à la London School of Economics et en diverses universités d'Angleterre et de Belgique. Il a également été Corresponding Fellow à la British Academy.

L'abondante bibliographie de Lanternari témoigne de la multiplicité de ses intérêts culturels; je me limiterai, à titre indicatif, à une sélection d'ouvrages, en laissant de côté les nombreux articles : La grande festa (1959); Occidente e Terzo Mondo (1967), Antropologia e imperialismo (1974), L'incivilimento dei barbari (1983), Medicina, Magia, religione, Valori (1994), Antropologia religiosa. Etnologia, storia, folklore (1997); Religione, magia e droga. Studi antropologici (2004).

Marcello MASSENZIO

Presidente dell'Associazione Internazionale Ernesto De Martino

Université Tor Vergata de Rome m.massenzio@tiscali.it

(traduction Giordana CHARUTY) 